\title{
De Quervain's subacute granulomatous thyroiditis: histological identification and incidence
}

\author{
G. MEACHIM AND M. H. YOUNG \\ From the Department of Pathology, University of Sheffield
}

SYNOPSIS The histological features of de Quervain's subacute granulomatous thyroiditis are described, on the basis of a study of six specimens. This condition, unlike Hashimoto's disease, rarely causes permanent hypothyroidism; its histological identification is thus of practical importance. Areas of thyroid affected by the disease show intrafollicular cellular infiltration, with partial or complete loss of colloid from infiltrated follicles, partial or complete disruption of their lining epithelium, and abnormalities of the basement membrane. These changes tend eventually to lead to replacement of the damaged follicle by a granuloma-like structure devoid of colloid content and without a recognizable epithelial lining. The disease also causes interfollicular fibrosis and an interstitial inflammatory cell reaction. The histological pattern is typically multiform. Formative follicle lesions present a striking appearance, aiding recognition of the disease. Some follicles contain numerous giant cells, often grouped around a central pool of residual colloid; others may contain a considerable proportion of neutrophil polymorphs or show radially aligned spindle-shaped cells.

A study has also been made of the incidence of de Quervain's thyroiditis in surgical material in Sheffield during the seven year period 1955-61. Only two examples were found in a total of 1,282 cases of primary thyroid disease, an incidence of 1.6 per $1,000(0 \cdot 16 \%)$; there is, however, reason to believe that the overall clinical incidence is higher than that indicated by the surgical figures.

De Quervain's thyroiditis (subacute granulomatous thyroiditis) is a relatively uncommon form of thyroid disease. De Quervain's early description (de Quervain, 1904) appeared in the German literature, but many of the more recent case reports have been from North America. For this reason a survey of the incidence of the condition in surgical material in Sheffield is now presented.

The clinical features of de Quervain's thyroiditis are well described in the North American literature (Crile and Rumsey, 1950; Lindsay and Dailey, 1954; Harland and Frantz, 1956; Volpé and Johnston, 1957; Woolner, McConahey, and Beahrs, 1957; and others). The disease is more common in women than in men, and its maximum incidence is in the fourth and fifth decades. The illness tends to have a fairly rapid onset. In some patients it is preceded by symptoms of an upper respiratory tract infection, with a sore throat, fever, and malaise. Thereafter the thyroid area becomes painful, the pain sometimes radiating to the jaw or ear. Dysphagia and

Received for publication 14 November 1962. hoarseness occasionally occur. On examination the thyroid is found to be swollen, tender, and firm. The whole gland may be diffusely involved, or the abnormal physical signs may be localized to one area and may then sometimes 'migrate' within the gland during the course of the illness. The thyroid enlargement can be accompanied by systemic symptoms, such as fatigue, malaise, and fever. The severity of the illness is very variable. At one extreme there are patients with severe thyroid pain and marked systemic symptoms; at the other extreme there are patients with little or no thyroid pain, in whom systemic symptoms are mild or absent (Crile and Rumsey, 1950). The duration of the illness is also variable, lasting from a few days to several months (Lindsay and Dailey, 1954). A single recurrence after the initial attack is said to be not uncommon but three separate consecutive attacks are rare (Ivy, 1961).

A temporary disturbance of gland function in severe cases of de Quervain's thyroiditis is described by many writers (Crile and Rumsey, 1950; McConahey and Keating, 1951; Lindsay and Dailey, 
1954; Harland and Frantz, 1956; Izak and Stein, 1956; Czerniak and Harell-Steinberg, 1957; Woolner et al., 1957; Volpé, Johnston, and Huber, 1958). In such cases there can be transient symptoms indicative of hyperthyroidism; the plasma protein-bound iodine level tends to be high, but, in contrast, iodine uptake by the gland in vivo tends to be diminished. Microautoradiography shows no iodine uptake by the epithelium of diseased follicles (Woolner et al., 1957). It is suggested that the damaged follicles are not only unable to synthesize new hormone but lose their storage function, causing flooding of the circulation with hormonally active iodinated material (Ingbar and Freinkel, 1958; Vanderlinde and Milne, 1960). If the hormone stores are exhausted before the disease subsides a temporary hypothyroid phase may next follow but the majority of patients eventually become euthyroid and persistent hypothyroidism is rare (Ivy, 1961). Persistent hyperthyroidism beginning during or after the illness is also uncommon, and is possibly due to coincidental frank Grave's disease (Sheets, 1955; Woolner et al., 1957) rather than to a true causal relationship as suggested by Perloff (1956).

Patients with de Quervain's thyroiditis often have a high erythrocyte sedimentation rate (Crile and Rumsey, 1950; Lindsay and Dailey, 1954). Cases with a normochromic anaemia have been described by Gross (1955) and by Skillern, Nelson, and Crile (1956) but leucocytosis is infrequent (Crile and Rumsey, 1950; Lindsay and Dailey, 1954). The disease is quite distinct from the rare acute suppurative thyroiditis due to infection of the gland by pyogenic bacteria (Harland and Frantz, 1956).

If surgical exploration is carried out the gland may be found to be loosely or firmly adherent to surrounding structures (Lindsay and Dailey, 1954; Gross, 1955; Harland and Frantz, 1956; Woolner et al., 1957) but there is usually no extensive neighbourhood spread by invasive fibrosis as is seen in Riedel's disease (Crile and Rumsey, 1950; Woolner et al., 1957). The cut surface of affected areas is firm and white or yellow-white (Woolner et al., 1957).

\section{HISTOLOGICAL IDENTIFICATION}

The histological features of de Quervain's thyroiditis have been studied in six cases. The age and sex of the patients and the sources of the material are shown in Table 1. Two cases were from Sheffield, three from the Sheffield Region, and one from Uganda.

Paraffin sections were stained by Ehrlich's haematoxylin and eosin, periodic-acid Schiff (P.A.S.), and Foot's modification of Gomori's reticulin method.
TABLE I

SEX AND AGE OF SIX CASES OF DE QUERVAIN'S THYROIDITIS AND SOURCES OF MATERIAL

\begin{tabular}{lll} 
Source & Sex & Age \\
\hline Mansfield & F & 50 \\
Leicester & M & 36 \\
Uganda & F & Adult (exact age not known) \\
Sheffield & F & 33 \\
Leicester & M & 48 \\
Sheffield & F & 53
\end{tabular}

MULTIFORM HISTOLOGICAL PATTERN Areas of thyroid tissue which have been affected by the disease show intrafollicular cellular infiltration, with partial or $\stackrel{\circ}{\circ}$ complete loss of colloid from infiltrated follicles and partial or complete disruption of their lining epithelium. There is also interfollicular fibrosis and an interstitial inflammatory cell reaction. The lesions tend to be patchy in distribution and in $\stackrel{\infty}{0}$ them the stage reached by the destructive process ㅇ tends to vary from field to field. In formative lesions follicles at differing stages of involvement inter- 3 mingle with one another and with uninfiltrated fol- $\stackrel{2}{<}$ licles. Later destructive lesions show mainly fibrous $\vec{\theta}$ tissue in which there are often granuloma-like foci $\stackrel{\circ}{\omega}$ apparently marking the site of disrupted follicles. In five of the six cases both formative lesions and, later, fibrous lesions are apparent; in the sixth case scarred areas are the dominant feature and formative lesions of a fully characteristic pattern are absent.

INTRAFOLLICULAR LEUCOCYTES The intrafollicular infiltrate, in what seems to be its earliest form, tends to consist mainly of large mononuclear cells (Fig. 1). These are accompanied by a variable number of lymphocytes and neutrophils. In some of the cases neutrophil infiltration is prominent in some follicles (Fig. 2) but in other cases intrafollicular polymorphs are mainly few or absent.

INTRAFOLLICULAR GIANT CELlS As the lesion develops multinucleate giant cells appear within a 은 proportion of the affected follicles. As many as five $D$ to 10 giant cells can sometimes be seen within a single follicle (Figs. 3 and 4). The most common type of giant cell has its nuclei arranged in a complete $\sigma$ or incomplete ring around the periphery of the $N$ cytoplasm (Fig. 3). Other giant cell types also occur, N including one in which the nuclei form a central or $\bar{O}$ eccentric mass surrounded by the bulk of the cytoplasm.

INTRAFOLLICULAR SPINDLE-SHAPED CELLS In some of the cases certain follicles contain a variable number of spindle-shaped cells. These tend to be $\frac{D}{\mathbb{D}}$ aligned radially in the outer part of the follicle, $\frac{\Omega}{8}$ with their long axes pointing towards its centre $\varrho$ (Fig. 5). 


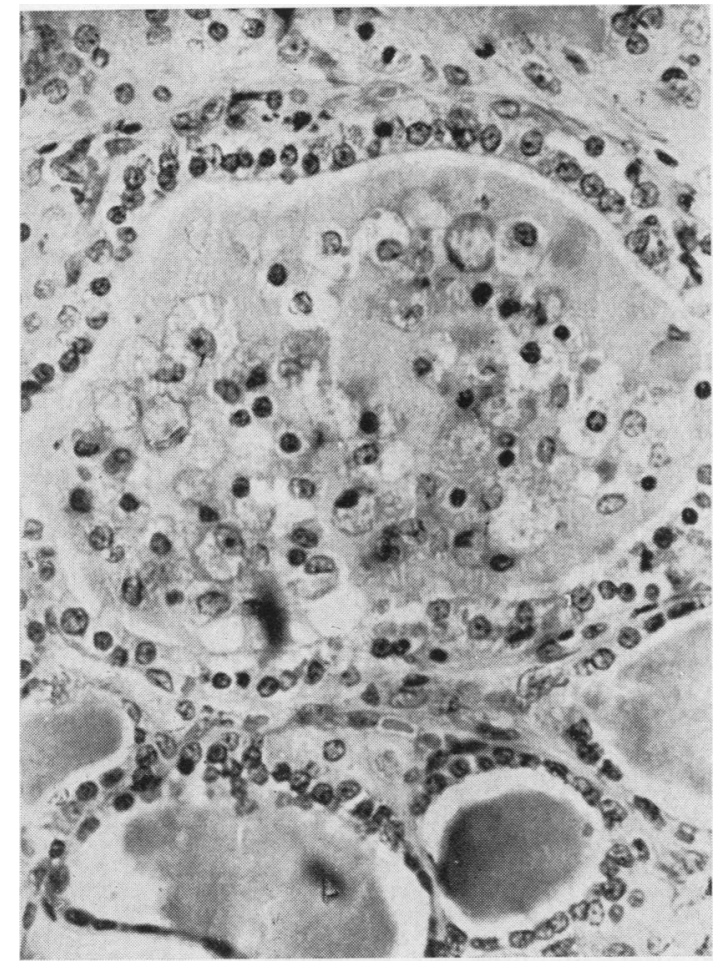

FIG. 1. Intrafollicular infiltrate in which large mononuclear cells predominate. De Quervain's tinyroiditis. Haematoxylin and eosin $\times 300$.

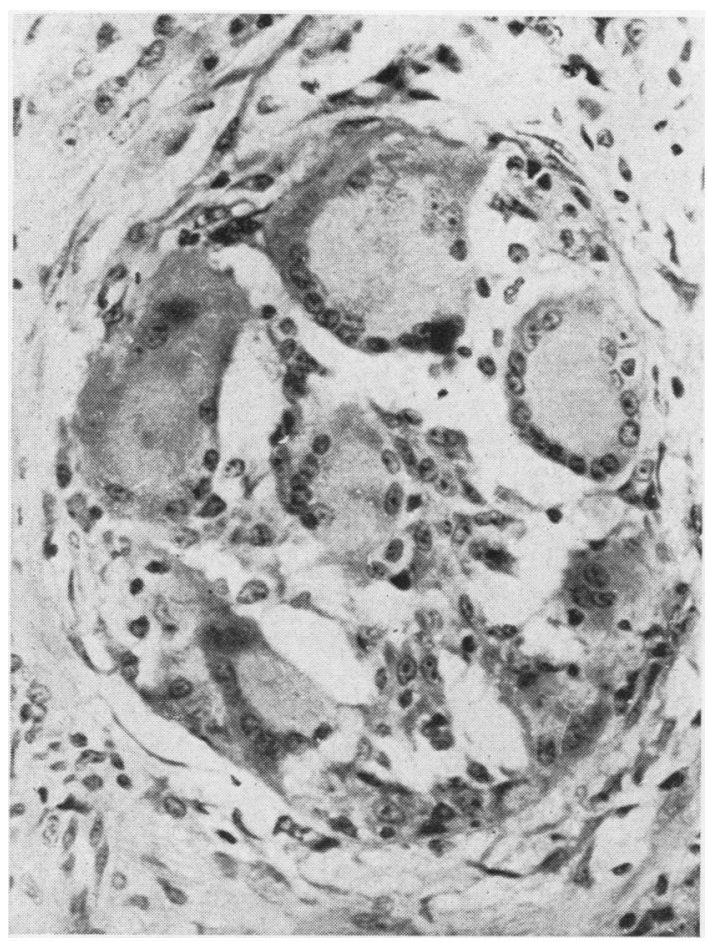

FIG. 3. Numerous multinucleate giant cells within a follicle. Note the absence of colloid. De Quervain's thyroiditis. Haematoxylin and eosin $\times 300$.

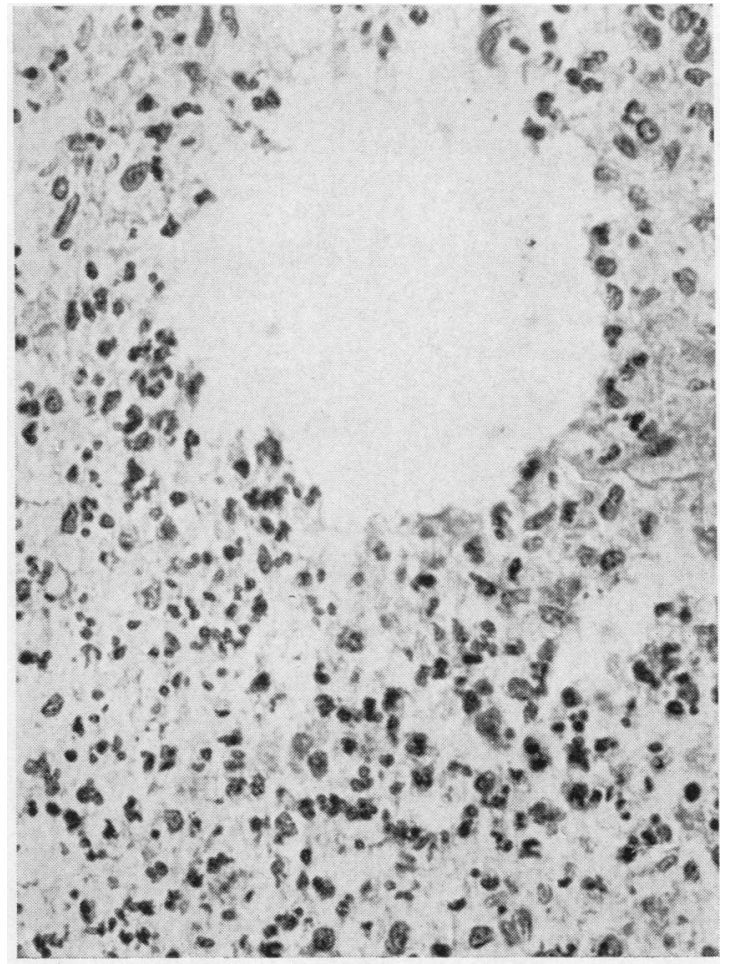

FIG. 2. Intrafollicular infiltrate containing many neutrophil polymorphs. De Quervain's thyroiditis. Haematoxylin and eosin $\times 300$.

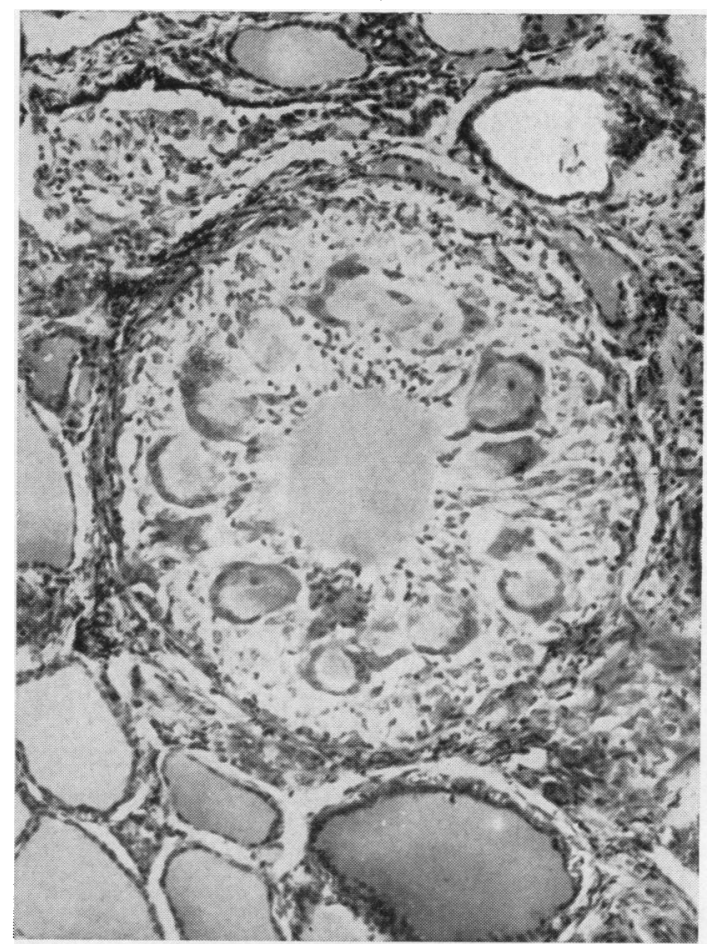

FIG. 4. Intrafollicular giant cells grouped around a central pool of colloid. De Quervain's thyroiditis. Haematoxylin and eosin $\times 125$. 


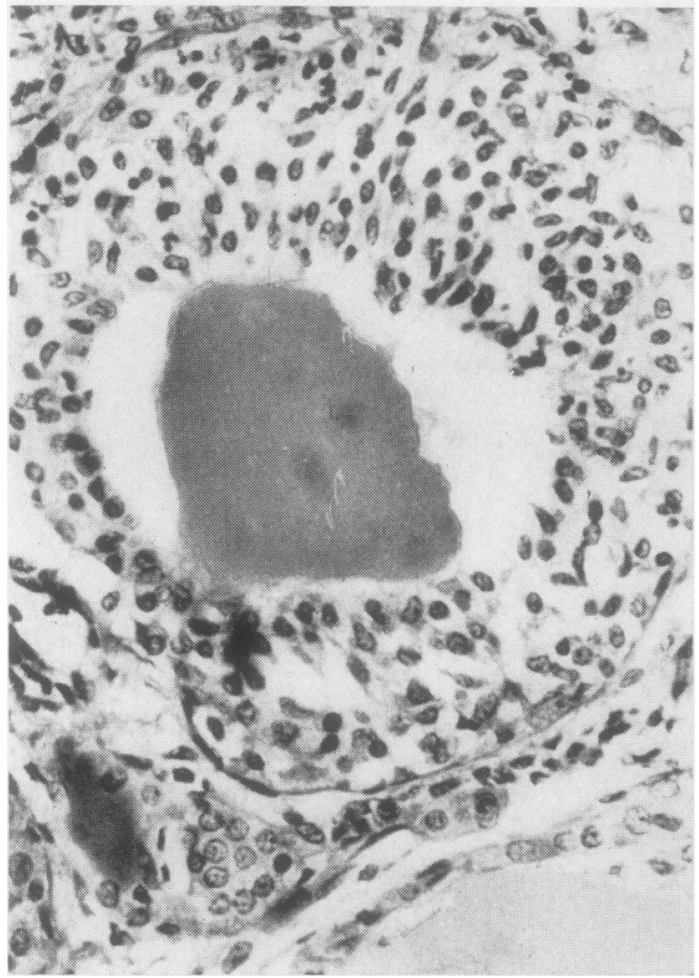

FIG. 5. Intrafollicular infiltrate containing radially-aligned spindle-shaped cells. De Quervain's thyroiditis. Haemato$x y l i n$ and eosin $\times 300$.

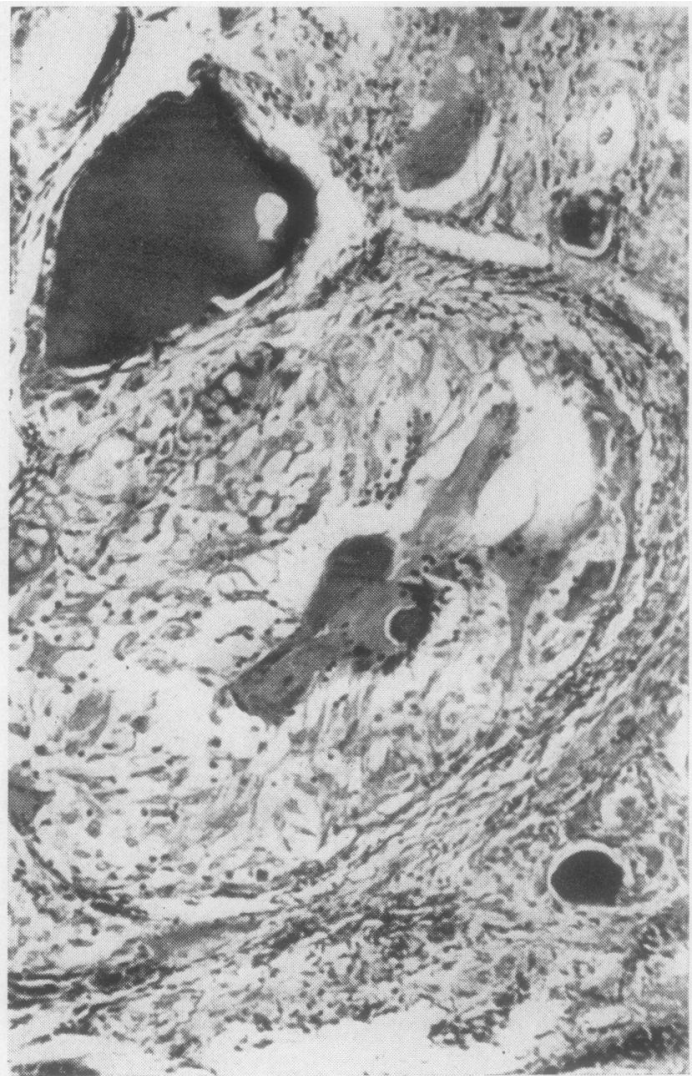

FIG. 6. 'Vacuolation' of infiltrated colloid. De Quervain's thyroiditis. P.A.S. $\times 300$.

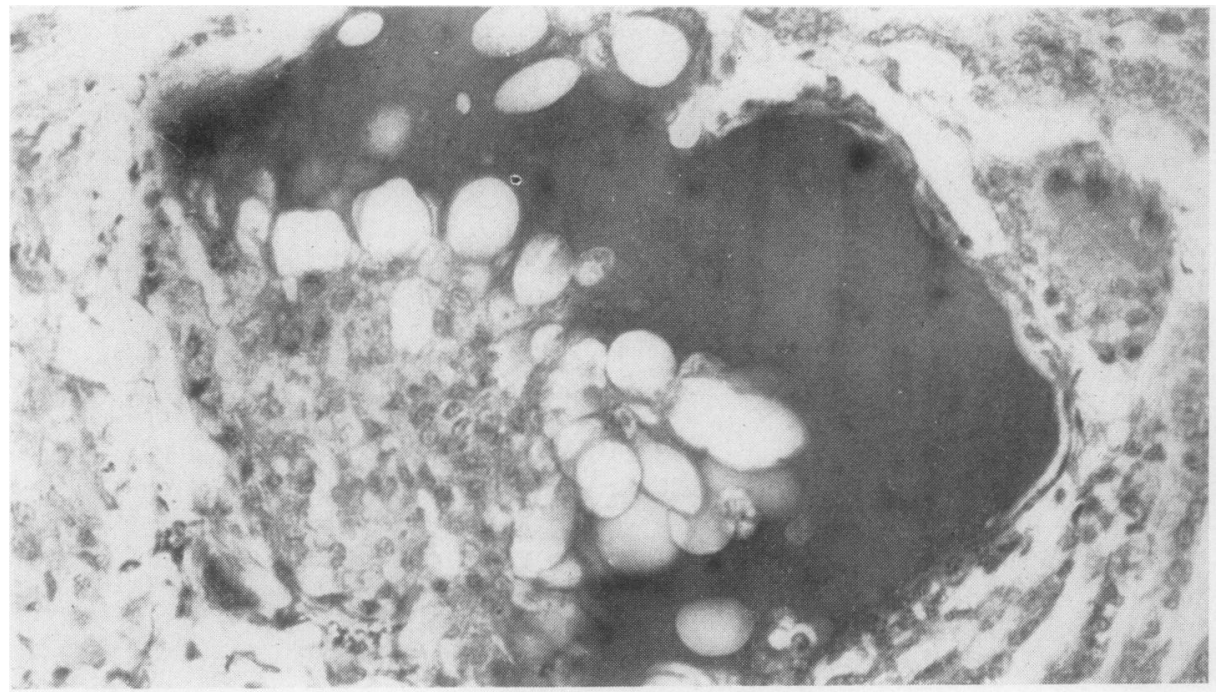

FIG. 7.

Multinucleate structures at one edge of a small pool of residual colloid. Note the rounded mass of colloid within the giant cell. De Quervain's thyroiditis.

P.A.S. $\times 125$. 
Certain of the constituents of the infiltrate are clearly leucocytes and macrophages but it is possible that shed or proliferating thyroid epithelium also contributes to the cells within the follicles. Thus it has been suggested that some of the multinucleate structures are formed by epithelial cells rather than by aggregates of macrophages (Lindsay and Dailey, 1954; Gross, 1955). Similarly the spindleshaped cells and some of the large mononuclear cells may perhaps be epithelial rather than mesenchymal in origin.

LOSS OF COLLOID The infiltrate occupies a part or the whole of the follicle. Where infiltrated the colloid appears vacuolated (Fig. 6) or is completely absent (Fig. 3). In the formative lesions a proportion of the follicles still contains a central pool of colloid, surrounded by cellular infiltrate often containing numerous giant cells (Fig. 4). This appearance is a highly characteristic feature of de Quervain's thyroiditis but it is not seen in the granulomatous areas thought to represent a later stage of the disease process.

Some of the large mononuclear cells within follicles contain fine droplets of P.A.S.-positive material consistent with colloid phagocytosis. Some of the giant cells also contain stainable colloid (Fig. 7) but in most of them the P.A.S. reaction is weak or absent. Perifollicular extravasation of stainable colloid seems to be rare (Lindsay, Dailey, Friedlander, Yee, and Soley, 1952), and it is difficult to accept that it is an important histological feature of the disease as is implied by Izak and Stein (1956).

EPITHELIAL DISRUPTION AND BASEMENT-MEMBRANE CHANGES Follicles with infiltration often show partial or complete disruption of their lining epithelium. There are also marked changes in the basement membrane of many affected follicles. The basement membrane then no longer forms a single compact ring round the follicle. Instead it is seen as several irregularly separated strands (Fig. 8), as if the fibres have sprung apart or undergone considerable 'duplication', as described by Stuart and Allan (1958). A second abnormality noted is the presence of breaks in the basement membrane, giving randomly orientated coarse and fine pieces of varying length (Fig. 9). Reticulin fibres are occasionally seen amongst the peripheral part of the intrafollicular infiltrate (Fig. 10).

GRANULOMA-LIKE STRUCTURES The follicle lesion, in what seems to be its formative stage, occurs mainly in large and medium-sized follicles. Where there has been complete loss of colloid the follicle tends to be replaced by a granuloma-like structure devoid of

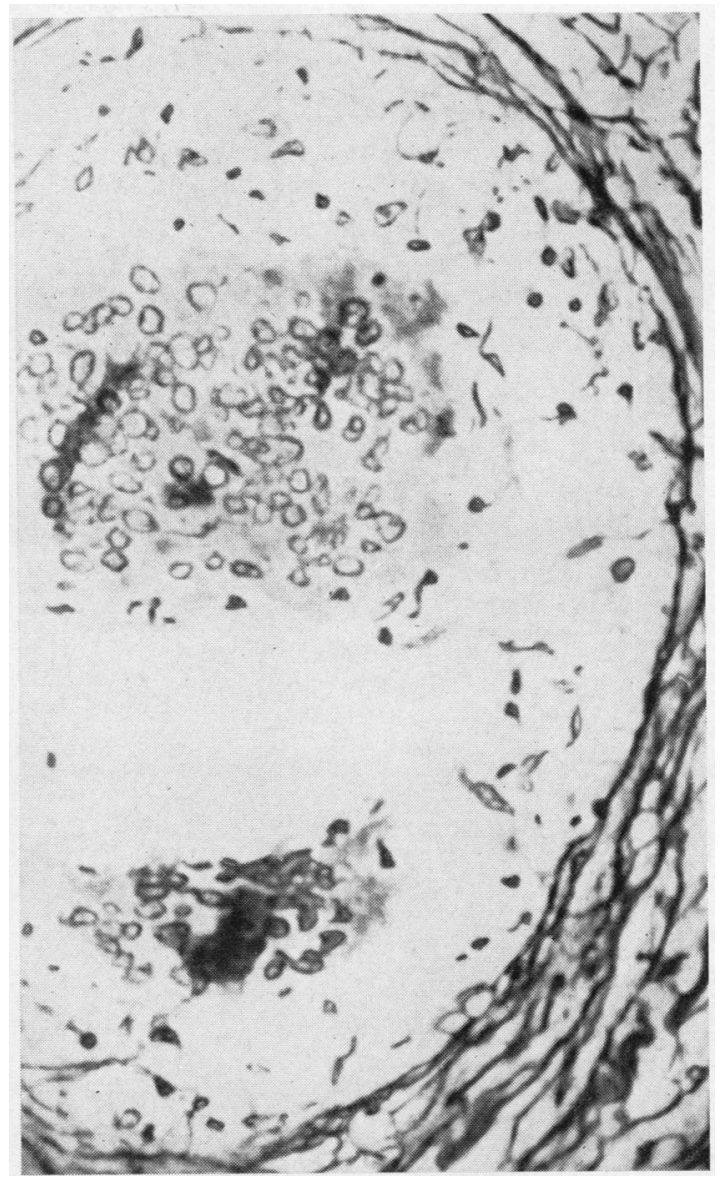

FIG. 8. Basement membrane of an affected follicle showing as several irregularly separated fibre strands. De Quervain's thyroiditis. Reticulin $\times 300$.

recognizable epithelial lining. The structure thus formed (Fig. 11) consists of giant cells, large mononuclear cells, some lymphocytes, and occasionally neutrophils.

INTERSTITIAL FIBROSIS AND INFLAMMATORY CELL REACTION Interfollicular fibrosis is present in all the cases examined. The amount of the fibrosis usually varies from area to area. Some areas show concentric rings of reticulin fibre formation around groups of affected follicles (Fig. 12); a later form of the destructive lesion consists mainly of fibrous tissue, in which granuloma-like foci, and sometimes isolated giant cells, apparently mark the site of disrupted follicles (Fig. 13). Caseation does not occur. The proliferating interstitial fibrous tissue includes small blood vessels. It shows a moderate degree of inflammatory cell infiltration in which 
FIG. 9. Breaks in the follicle basement membrane. De Quervain's thyroiditis. Reticulin $\times 300$.

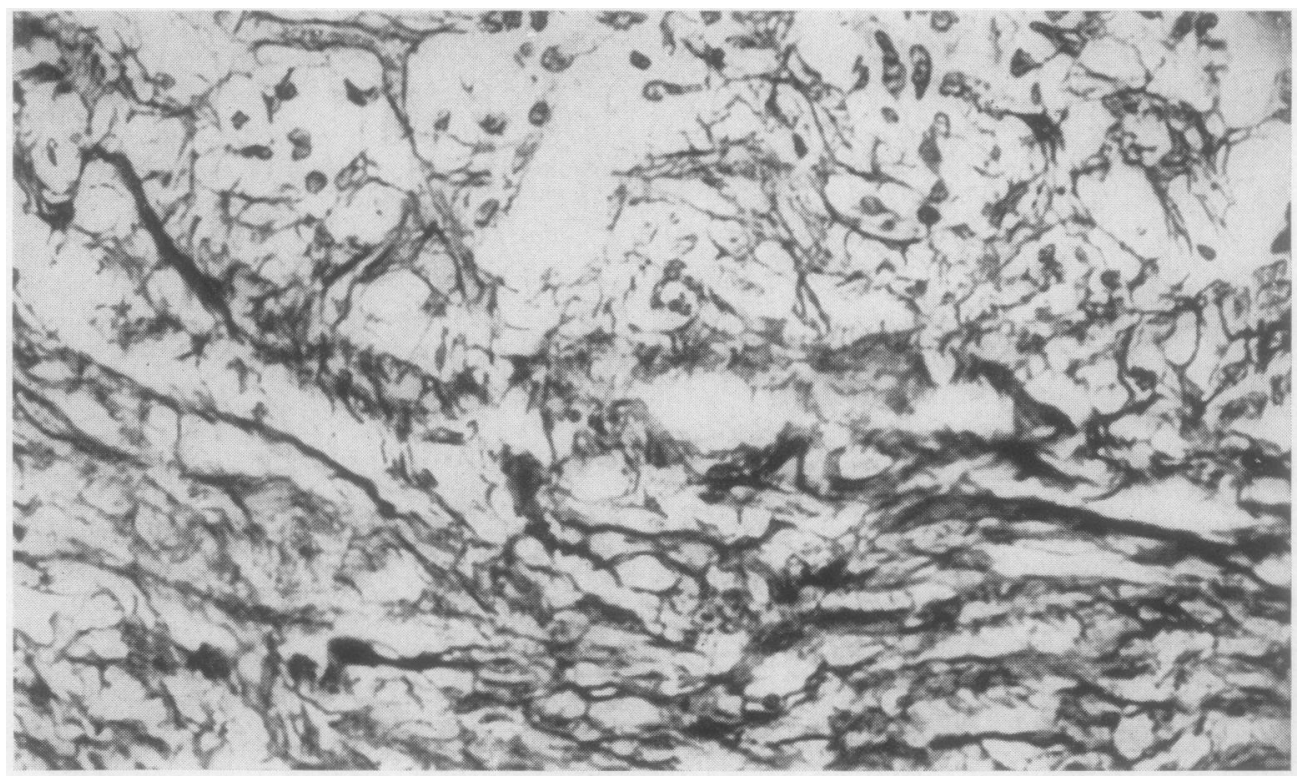

FIG. 10. Reticulin fibres amongst an intrafollicular infiltrate, which occupies the upper part of the field. De Quervain's thyroiditis. Reticulin $\times 300$. 


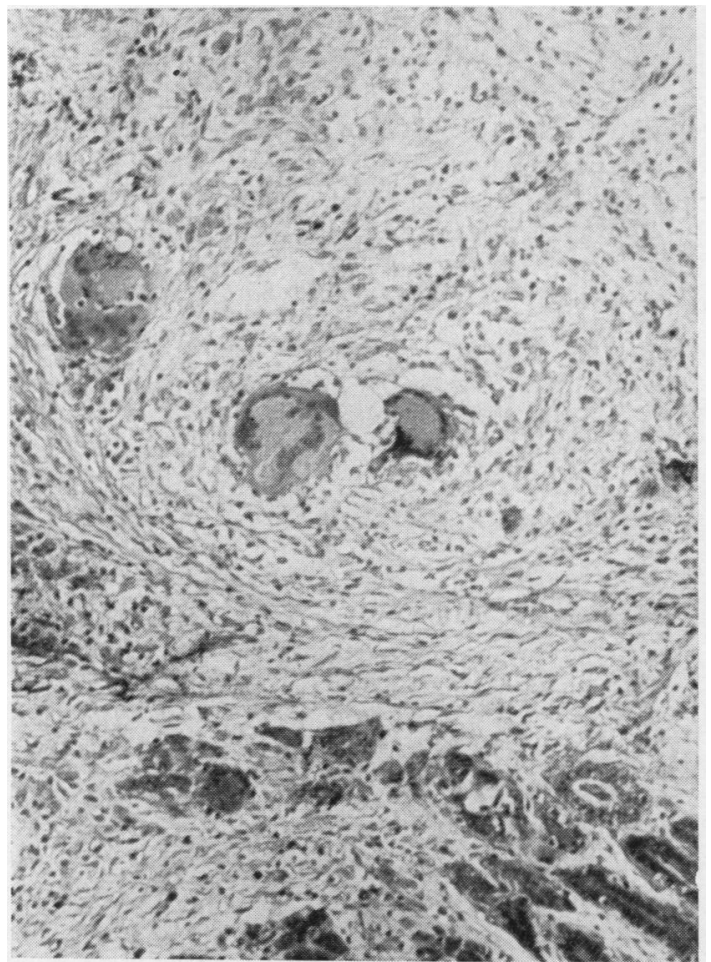

FIG. 11

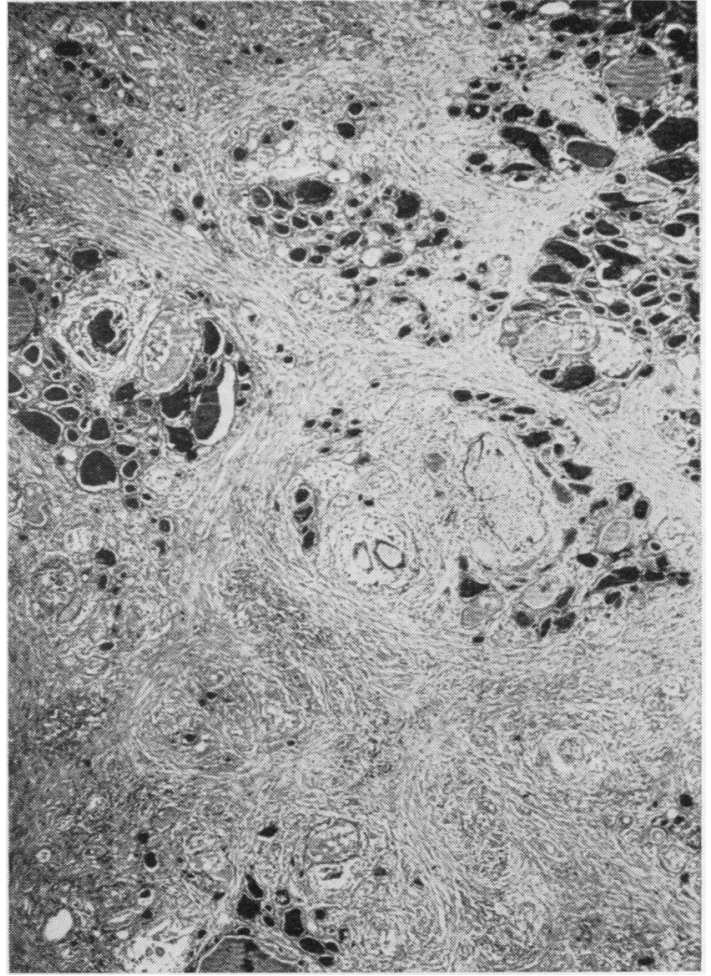

FIG. 12

FIG. 11. A 'granuloma' containing multinucleate giant cells. De Quervain's thyroiditis. Haematoxylin and eosin $\times 125$.

FIG. 12. Whorls of reticulin around groups of affected follicles. De Quervain's thyroiditis. Reticulin $\times 30$.

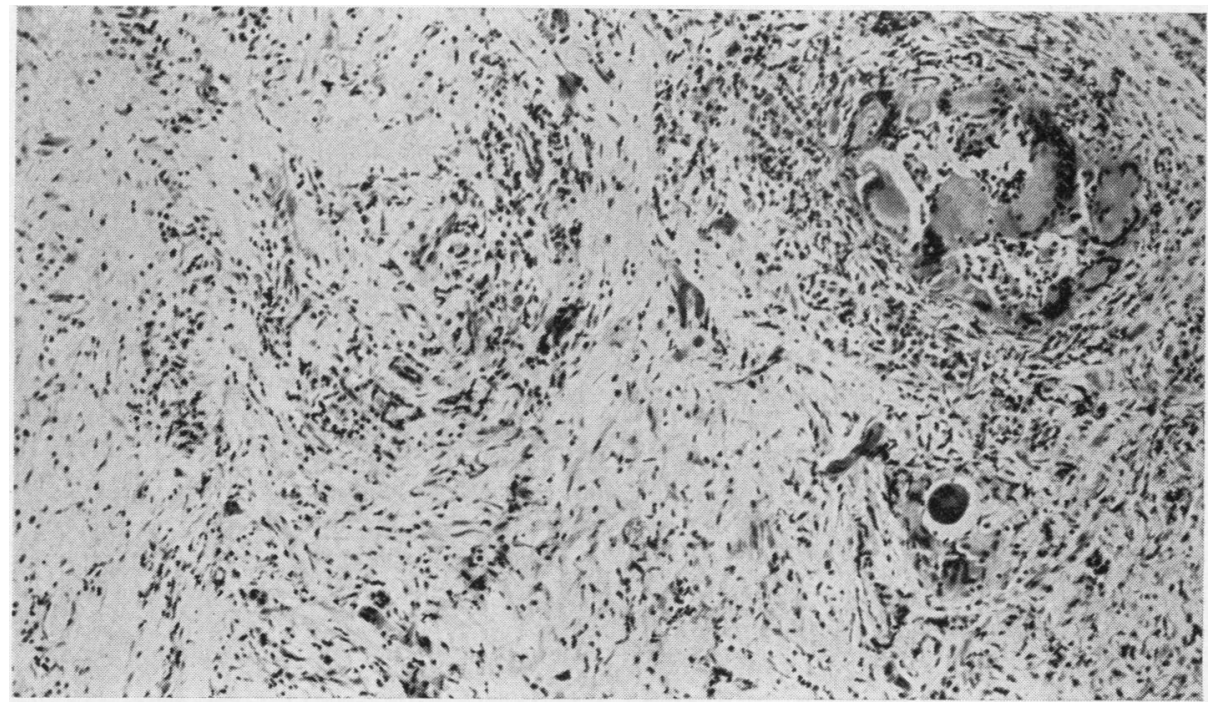

FIG. 13. An area consisting mainly of vascular fibrous tissue showing inflammatory cell infiltration.

Note the 'granuloma'. De Quervain's thyroiditis. Haematoxylin and eosin $\times 75$. 
lymphocytes tend to predominate, accompanied by variable numbers of plasma cells, eosinophils, large mononuclear cells, and histiocytes.

GROUPS OF ABNORMALLY SMALL FOLLICLES In addition to the features already described, some of the fibrous areas contain irregular groups of abnormally small follicles which have an intact epithelial lining and are free from intrafollicular infiltration (Fig. 14). These small follicles are mostly lined by low columnar or cuboidal epithelium, although in a proportion of them the lining cells are flattened. Their colloid content is often pale-staining or absent but in some it forms a compact, deeply eosinophilic globule. They show perifollicular infiltration by lymphocytes together with a smaller proportion of plasma cells. The amount of this cellular infiltration is usually slight and not in excess of that seen elsewhere in the interstitial fibrous tissue. Askanazy cell change to epithelial forms with copious eosinophilic cytoplasm is not seen. It is uncertain whether the abnormally small follicles are atrophic or regenerative, but the apparent absence of increased mitotic activity in their epithelium perhaps favours the view of Woolner et al. (1957) that they are shrunken residual follicles. In one of the cases the small

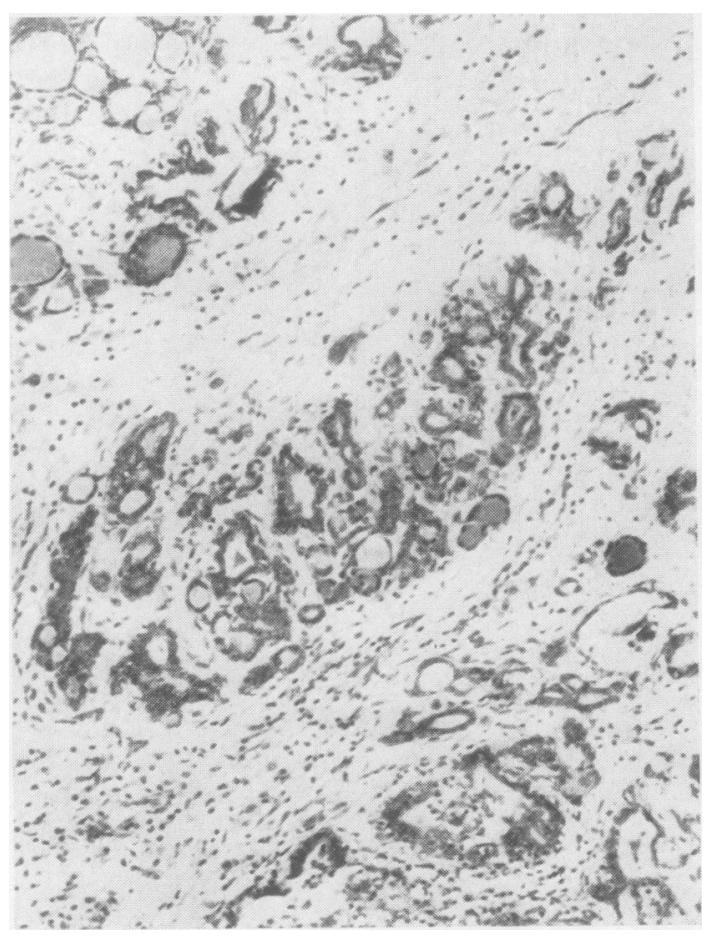

FIG. 14. Group of abnormally small follicles in de Quervain's thyroiditis. Haematoxylin and eosin $\times 125$. follicles are accompanied by many solid, irregular masses of epithelial cells.

EPITHELIAL REGENERATION In severely scarred areas there is clearly a permanent loss of glandular tissue. However, in less scarred areas Lindsay and Dailey (1954) have described epithelial regeneration by proliferation of residual lining cells at the edge of the follicle. The new follicles thus formed are at first small, but increase in size as they acquire colloid content (Lindsay and Dailey, 1954). It is possible that epithelial regeneration may also occur by multiplication of surviving normal follicles.

\section{INCIDENCE OF DE QUERVAIN'S THYROIDITIS}

The study of the incidence of de Quervain's thyroiditis was based on a retrospective analysis of all surgical specimens showing primary thyroid disease submitted for pathological examination in the hospitals in Sheffield during the seven-year period 1955-61 inclusive. Necropsy material was excluded. All sections reported as Hashimoto's or Riedel's disease were reviewed, together with any others in which the report mentioned giant cells, pseudotubercle formation, or fibrosis. For the rest of the cases the histological diagnosis given or implied was usually accepted without further verification.

The incidence of the various forms of thyroid disease in the Sheffield surgical material during the seven-year period of the survey is shown in Table II. Where it was apparent that thyroid tissue had been submitted from the same patient on two or more occasions, a single entry was recorded under the final diagnosis. In eight patients a needle biopsy specimen only was available.

For the purpose of the survey Riedel's disease is shown separately from Hashimoto's disease, although it is perhaps debatable whether it is merely a fibrous variant of Hashimoto's disease (Vaux, 1938) or a separate, very rare entity (Doniach, 1960). Both the cases listed as 'Riedel's disease' in Table I showed evidence of invasive fibrosis extending beyond the confines of the gland (Doniach, 1960).

It will be seen from Table II that there were only two examples of de Quervain's thyroiditis in a total of 1,283 cases of primary thyroid disease, giving an incidence of 1.6 cases per $1,000(0.16 \%)$ in the Sheffield surgical material.

\section{DISCUSSION}

Areas of thyroid tissue affected by de Quervain's thyroiditis show intrafollicular cellular infiltration, with partial or complete loss of colloid from infiltrated follicles and partial or complete disruption of their 


\section{TABLE II}

ANALYSIS OF SURGICAL SPECIMENS SHOWING PRIMARY THYROID DISEASE EXAMINED IN SHEFFIELD HOSPITALS DURING PERIOD 1955-61

Diagnosis

Simple, non-toxic goitre

Simple nodule

Hürthle cell tumour

Thyrotoxicosis

Carcinoma of thyroid

Hashimoto's disease

Riedel's disease

de Quervain's thyroiditis

Total
Number of Cases

631
161
5
313
96
73
2
2

lining epithelium. These follicular changes tend eventually to lead to the formation of granulomalike structures devoid of colloid content and without a recognizable epithelial lining. There is also interfollicular fibrosis and an interstitial inflammatory cell reaction. The histological pattern is usually multiform, showing formative follicle lesions at differing stages of involvement, together with mainly fibrous areas representing a later stage of the disease process.

De Quervain's thyroiditis has a striking histological appearance when well-formed intrafollicular lesions are seen. Follicles containing numerous giant cells, often surrounding a central pool of colloid, are a characteristic feature of the disease (Fig. 4); some cases also show occasional follicles in which there is intense neutrophilic infiltration (Fig. 2) or proliferation of radially aligned spindle-shaped cells (Fig. 5). Intrafollicular cellular infiltration is not, however, confined to this disease. In simple or toxic goitre scattered follicles sometimes contain large mononuclear cells, giving an appearance very similar to that seen in what appears to be the earliest lesion of de Quervain's thyroiditis (Fig. 1). Glands recently treated with radioactive iodine can show epithelial disruption, intrafollicular mononuclear and multinucleate cells, and loss of colloid from the follicle (Lindsay and Dailey, 1954; Curran, Eckert, and Wilson, 1958). Intrafollicular 'giant cells', individually similar to those of de Quervain's thyroiditis, are sometimes seen in Hashimoto's disease but they occur mainly in abnormally small follicles and it is unusual to see more than two in any one follicle (Fig. 15); none of the 73 cases of Hashimoto's disease reviewed during the present study showed any follicles containing numerous giant cells surrounding a central pool of colloid.

If the characteristic intrafollicular lesions are not seen, caution is necessary before accepting thyroid 'granulomata' or interstitial giant cells as histological evidence of de Quervain's disease. Unusual 'granulomata' have been noted in the thyroid of a

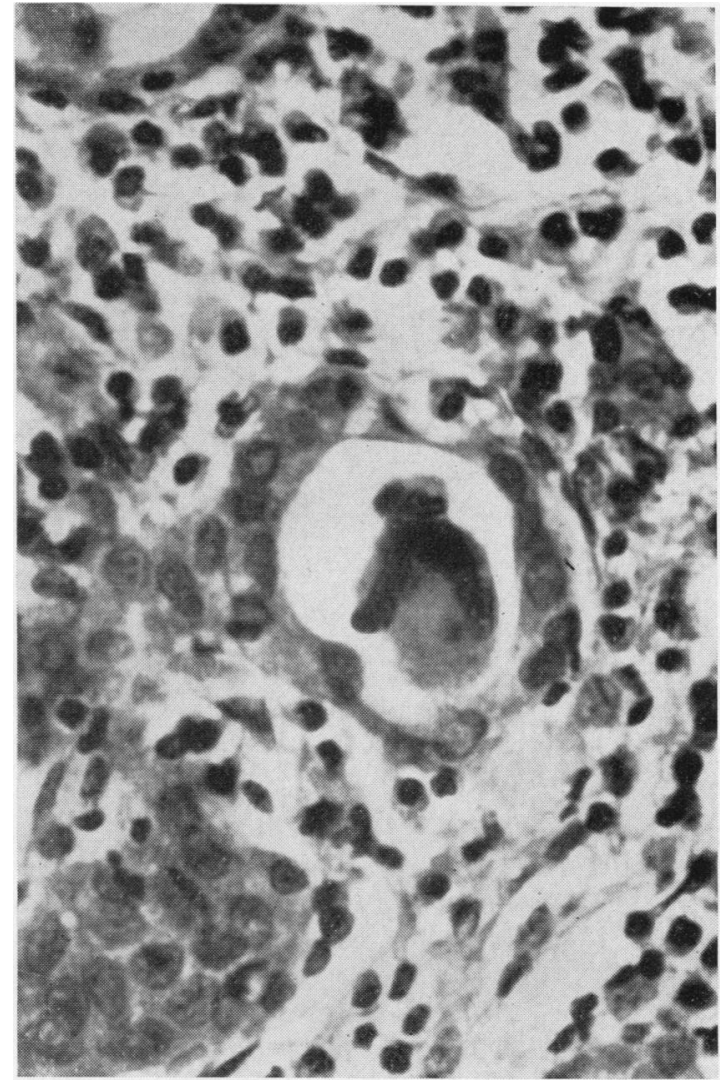

FIG. 15. Intrafollicular 'giant cell' in Hashimoto's disease. Compare with Figure 4. Haematoxylin and eosin $\times 500$.

patient with perchlorate-treated thyrotoxicosis (Fig. 16), and the present study also revealed an example of thyroid amyloidosis in which occasional interstitial giant cells are present. Douglass and Jacobson (1957) describe multinucleate cells in some of their fibrotic thyroids from patients with adult myxoedema. 'Tubercle-like follicles' are depicted by Vaux (1938) in two cases of 'atypical' lymphadenoid goitre, although inspection of her illustrations suggests that these two cases may, in fact, have been examples of de Quervain's disease.

It is relevant to compare de Quervain's thyroiditis with Hashimoto's disease. A certain group of patients with Hashimoto's disease can show an initial clinical presentation similar to that of de Quervain's thyroiditis (Doniach, Hudson, and Roitt, 1960). There are, however, important differences between the two conditions, both in their aetiology and, especially, in their subsequent behaviour. Sound evidence has been published that at least some cases of de Quervain's thyroiditis are associated with infection of the gland by mumps virus (Eylan, 


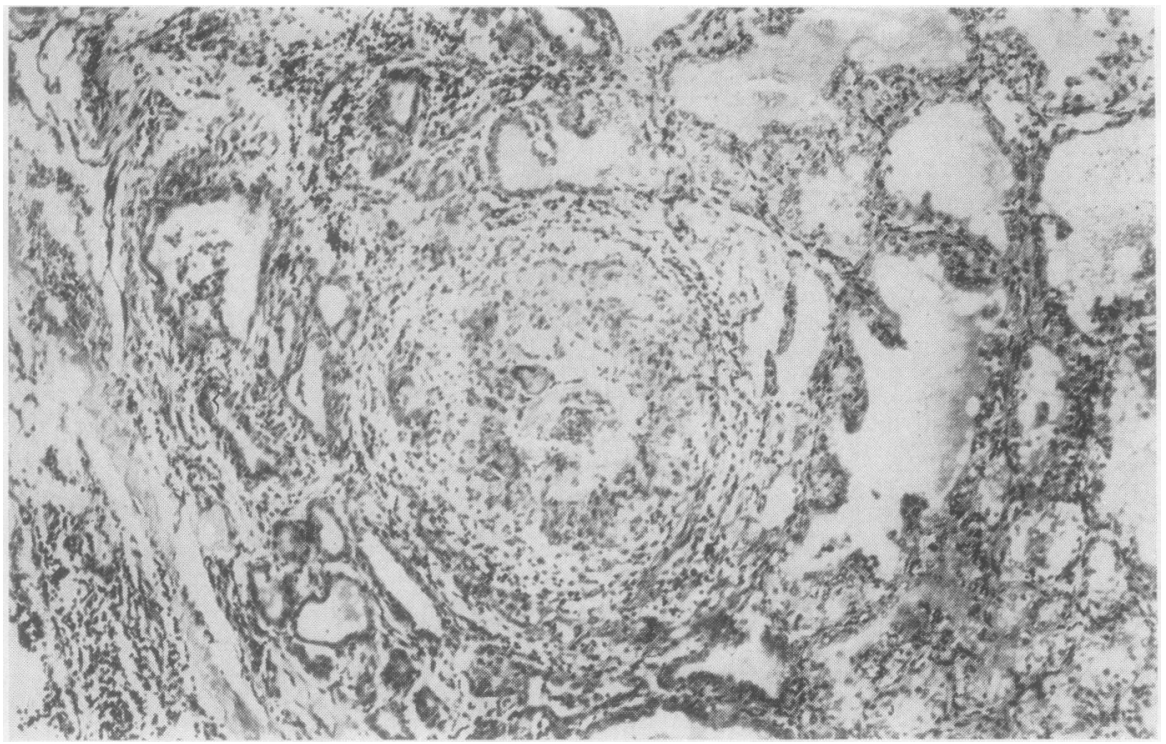

F1G. 16. Unusual 'granuloma' in perchlorate-treated के thyrotoxicosis. Haematoxylin and eosin $\times 75$.

Zmucky, and Sheba, 1957; Felix-Davies, 1958); no such direct causation by a specific microorganism has yet been convincingly demonstrated in Hashimoto's disease. Again, although auto-antibodies to thyroid antigens are sometimes found in de Quervain's thyroiditis, the auto-immune process does not usually tend to persist as in Hashimoto's disease (Doniach et al., 1960). Temporary hypothyroidism can occur, but permanent myxoedema is rare if patients submitted to subtotal thyroidectomy or thyroid irradiation are excluded (Crile and Rumsey, 1950; Fraser and Harrison, 1952; Harland and Frantz, 1956; Moldover, 1956; Woolner et al., 1957; Bergen, 1958; Volpé et al., 1958; Vanderlinde and Milne, 1960). Cases of permanent myxoedema which cannot be attributed to subtotal thyroidectomy are, however, recorded by Lindsay and Dailey (1954), Woolner et al. (1957) and Ivy (1961). De Quervain's thyroiditis may also have been responsible for the three cases of myxoedema following mumps discussed by Doniach et al. (1960).

The survey of the Sheffield surgical material has shown only two cases of de Quervain's thyroiditis during seven years in a city with approximately half a million inhabitants. However, surgical material serves only as a limited guide to the overall incidence of the disease. Patients with a mild attack may not have been referred to hospital, and of those admitted by no means all will necessarily have been subjected to surgical exploration of the gland. Accepting these limitations, it is of interest to compare the Sheffield figures with those obtained by Lindsay and Dailey (1954) in San Francisco and with those published by Harland and Frantz (1956) from New York. Lindsay and Dailey found an incidence of 3.2 cases per 1,000 in their series of 7,263 thyroidectomies, Harland and Frantz (1956) show a similar incidences of 3.6 cases per 1,000 in 7,448 thyroid operations The Sheffield figure of 1.6 cases per 1,000 perhapso indicates a somewhat lower incidence of de Quervain's thyroiditis here than in North America, but doeso not lend definite support to the clinical impression (Doniach et al., 1960) that there is a marked geo graphical variation in the frequency of the disease

We are very grateful to Dr. A. G. Ackerley, Professor: D. H. Collins, Dr. W. M. Goldie, Dr. F. Lothe, Dr. A MacFarlane, Mr. J. N. Ward-McQuaid, and Dro E. Milford Ward for allowing us to use their materialo We are much indebted to Dr. J. L. Edwards, Dr. J. L. Emery, Dr. G. D. Powell, and Dr. A. J. N. Warrack fors giving us access to their laboratory files, and also tod Dr. J. L. Edwards and Professor G. M. Wilson for theio valuable comments. Mr. T. L. Platts has kindly assisted with the photomicrographs.

This study was suggested by Professor D. H. Collins N and we gratefully acknowledge his helpful interest and encouragement.

\section{REFERENCES}

Bergen, S. S. Jr. (1958). Arch. intern. Med., 102, 747. Crile, G., and Rumsey, E. W. (1950). J. Amer. med. Ass., 142, 458: Curran, R. C., Eckert, H., and Wilson, G. M. (1958), J. Path. Bact., 76, 541 . Czerniak, P., and Harell-Steinberg, A. (1957). J. clin. Endocr., 17 $\frac{\text { 17 }}{\mathrm{D}}$

Doniach, Deborah, Hudson, R. V., and Roitt, I. M. (1960). Brit. med(D J., $1,365$.

Doniach, I. (1960). In Recent Advances in Pathology, 7th ed., edited by C. V. Harrison, p. 241. Churchill, London. 
Douglass, R. C., and Jacobson, S. D. (1957). J. clin. Endocr., 17, 1354. Eylan, E., Zmucky, R., and Sheba, Ch. (1957). Lancet., 1, 1062.

Felix-Davies, D. (1958). Ibid., 1, 880.

Fraser, R., and Harrison, R. J. (1952). Ibid., 1, 382.

Gross, S. (1955). Arch. Path., 59, 412.

Harland, W. A., and Frantz, Virginia K. (1956). J. clin. Endocr., 16, 1433

Ingbar, S. H., and Freinkel, N. (1958). Arch. intern. Med., 101, 339. Ivy, H. K. (1961). J, clin. Endocr., 21, 1384.

Izak, G., and Stein, Y. (1956). Lancet, 1, 225.

Lindsay, S., and Dailey, M. E. (1954). Surg. Gynec. Obstet., 98, 197.

,-- Friedlander, Jean, Yee, G., and Soley, M. H. (1952). J. clin. Endocr., 12, 1578.

McConahey, W. M., and Keating, F. R. Jr. (1951). Ibid., 11, 1116.
Moldover, A. (1956). Arch. intern. Med., 98, 322.

Perloff, W. H. (1956). J. clin. Endocr., 16, 542.

Quervain, F. de (1904). Mitt. Grenzgeb. Med. Chir., 2nd suppl., p. 1. Sheets, R. F. (1955). J. Amer. med. Ass., 157, 139.

Skillern, P. G., Nelson, H. E., and Crile, G. Jr. (1956). J. clin. Endocr., $16,1422$.

Stuart, A. E., and Allan, W. S. A. (1958). Lancet., 2, 1204.

Vanderlinde, R. J., and Milne, J. (1960). J. Amer. med. Ass., 173, 1799.

Vaux, Dorothy M. (1938). J. Path. Bact., 46, 441.

Volpé, R., and Johnston, M. W. (1957). Canad. med. Ass. J., 77, 297.

_ and Huber, Norma (1958). J. clin. Endocr., 18, 65.

Woolner, L. B., McConahey, W. M., and Beahrs, O. H. (1957). Ibid., $17,1202$. 